Revista Aspas

ppgac - USP

Forma Livre

\title{
MEMÓRIAS DO PROGRAMA VOCACIONAL: MOVIMENTOS AO REDOR DE EMANCIPAÇÃO, IGUALDADE E POLÍTICA
}

MEMORIES FROM VOCATIONAL PROGRAM: MOVEMENTS AROUND EMANCIPATION, EQUALITY AND POLITICS

MEMORIAS DEL PROGRAMA VOCACIONAL: MOVIMIENTOS ACERCA DE EMANCIPACIÓN, IGUALDAD Y POLÍTICA

Miguel Prata

Miguel Prata

Mestre em Teoria e Prática do Teatro pelo Departamento de Artes Cênicas da Escola de Comunicações e Artes da Universidade de São Paulo. E-mail:1miguelprata@gmail.com 


\section{Resumo}

O presente artigo toma como ponto de partida fragmentos da revista Vocacional Memória: percorrendo vozes e ecos de um projeto público. Mirando a memória do Vocacional, o texto objetiva pensar essa política pública partindo do contexto de sua criação, apontando alguns desdobramentos e efeitos, movimentando algumas ideias em torno da emancipação intelectual associada a ideias sobre igualdade e política na leitura do filósofo argelino Jacques Rancière.

Palavras-chave: políticas públicas, arte-educação, emancipação intelectual, igualdade das inteligências, pluriversalidade.

\section{Abstract}

This article takes as a starting point fragments of the magazine Vocational Memory: traveling through voices and echoes of a public project. Looking at Vocational Program memory, the text aims to think about this public policy from the context of its creation, pointing out some outcomes and effects, developing some ideas around intellectual emancipation associated with ideas about equality and politics by the reading of the algerian philosopher Jacques Rancière.

Keywords: public policy, art education, intellectual emancipation, equality of intelligence, pluriversality.

\section{Resumen}

Este artículo toma como punto de partida fragmentos de la revista Vocacional Memoria: trasladando entre voces y ecos de un proyecto público. Mirando la memoria del Programa Vocacional, el texto pretende reflexionar sobre esta política pública a partir del contexto de su creación, señalando algunos despliegues y efectos, moviendo algunas ideas en torno de la emancipación intelectual asociada a las ideas sobre igualdad y política en la lectura del filósofo argelino Jacques Rancière.

Palabras clave: políticas públicas, educación artística, emancipación, igualdad de las inteligencias, pluriversalidad. 
O presente artigo toma como ponto de partida e é atravessado por fragmentos da história do Programa Vocacional, política pública de formação artística, lançada em 2001, pela Secretaria Municipal de Cultura de São Paulo. Mirando estes fragmentos a partir da publicação: Vocacional Memória: percorrendo vozes e ecos de um projeto público; o texto objetiva pensar essa política partindo do contexto de sua criação, apontando alguns desdobramentos e efeitos, movimentando algumas ideias em torno da emancipação intelectual associada a ideias sobre igualdade e política na leitura do filósofo argelino Jacques Rancière. A publicação que nos atravessa reúne falas que tratam de ambientes e contextos bem diferentes do Vocacional. Compreende o trabalho de muitas e muitos artistas que passaram pelo programa, e foi composta como uma dramaturgia, não como história oficial'. Optamos por manter os fragmentos da publicação como imagens para serem lidos como pedaços de memórias que interferem no texto e podem deslocar seu sentido. A memória é também assunto importante neste artigo, por isso, pensemos também em chamá-lo de ensaio. Atuei no Vocacional como artista orientador de 2014 a 2017, e como articulador de metodologias e instrumentais em 2019. Em 2020, recebi o convite para entrar na Secretaria Municipal de Cultura para realizar a Coordenação Técnica dos Programas Piá e Vocacional. A palavra ensaio aqui é tratada na aliança com Michel de Montaigne, na busca por uma escrita tateante de quem "não sabe e procura e como conclusão [se atém] simplesmente às ideias comuns e legítimas. Não ensina, conta" (MONTAIGNE, 1972, p. 372).

$\mathrm{Na}$ relação com a trajetória de um programa de 20 anos, não pretendemos dar conta de toda sua história e complexidade. A mirada também não se propõe a uma análise das propostas como instituição pública. Tentaremos apenas nos deter sobre alguns espaços que se abrem nos encontros, procurando deixar que trechos de memória atravessem o modo

\footnotetext{
1 Entre 2014 e 2016, o grupo de trabalho Vocacional Memória realizou ações mirando a trajetória do Vocacional: foram encontros públicos e entrevistas com antigos coordenadores, encontros com grupos, artistas orientadores e artistas vocacionados de épocas diferentes do programa. Todos esses materiais criados pelo GT reunidos na publicação de 2016 estão disponíveis em: http://supervisaodeformacao.prefeitura.sp.gov.br/index.php/cmd-vocacional/acessado em 09/07/2021
} 
Memórias do Programa Vocacional: movimentos ao redor de emancipação, igualdade e política

como estamos abordando os assuntos. Como forma de colocar o que delineia esses encontros que observaremos, iniciemos com a leitura de um trecho do último edital publicado para contratação da equipe de artistas de 2021, o qual voltaremos a abordar mais adiante. Nele, o Vocacional está definido como um "programa de formação artística, fundamentado pela ideia de cidadania cultural". Aponta como objetivo "a instauração de processos emancipatórios a partir de práticas artístico-pedagógicas, voltadas a um público acima de 14 anos". Ainda destaca como finalidade "promover a ação e a reflexão sobre a prática artística, a cidadania, a ocupação dos espaços públicos da cidade". Segundo o mesmo edital, o programa atua por meio de encontros em que se estabelece "um lugar de diálogo entre artista orientador e artista vocacionado (público atendido), seus históricos e realidades"3.

\footnotetext{
${ }^{2}$ Alusão à ideia abordada pela filósofa Marilena Chauí, Secretária de Cultura durante a gestão da prefeita Luiza Erundina entre 1989 e 1992, tomada como referência para a criação do Núcleo em 2001. Não aprofundaremos o conceito aqui, ver CHAUÍ, 2006.

${ }^{3}$ Edital disponível no link: http://supervisaodeformacao.prefeitura.sp.gov.br/index.php/editaisformacao-smc-2021/acessado em: 09/07/2021
} 
Figura 1: Página 95 da revista Vocacional Memória, publicada em 2016 pelo Grupo de Trabalho Vocacional Memória.

\section{WM COHTEYT PARA Q VQCACHAML}

(Artista Orientador): Uma memória do Vocacional de 2015. Ano passado, eu orientava no CEU Quinta do Sol. Eu orientava todo domingo, às manhăs. E sempre que eu chegava no CEU, lá pelas 10 da manhâ, o CEU estava lotado e tinha gente até indo embora, que tinha chegado às 07 da manhã para jogar bola, para usar a piscina. E numa manhã como qualquer outra, num domingo muito, muito quente, como essa semana, eu estava chegando no CEU, e eu sempre entro no CEU, eu venho pela rua de trás do CEU. E eu vi uns meninos pulando umas grades do CEU, uma meia dúzia de meninos. Tranquilo. Não era a primeira vez que eu tinha visto eles fazerem isto. Quando eu cheguei no CEU, eu vi que a piscina estava claramente lotada, 200, 300 pessoas. E tudo bem também, normal, como qualquer manhã quente no CEU. Aí entrei no teatro para a minha orientação. Uma menina chegou e mostrou para mim um vídeo. E, no vídeo, tinha as mesmas pessoas na piscina, tomando seu banho, felizes, brincando e tudo mais. E eu falei: eu vi essas pessoas lá. E ela falou para mim: hoje a piscina está fechada. E eu respondi: como assim? Ela me disse: hoje não tem salva-vidas e por isso não abriram a piscina. Ou seja, 200, 300 pessoas pularam os muros e as grades para usar a piscina. Meia hora depois, o segurança terceirizado chamou a polícia sucateada que entrou com um carro que nunca havia entrado no CEU e pediu delicadamente que $200 / 300$ pessoas que estavam tomando seu banho saíssem pela porta da frente, descalças. De quem é o espaço público? De quem é o desejo público?

No ano de 1988, artistas e moradores da região da Lapa se organizaram e invadiram o Tendal. O espaço, que serviu de matadouro no início daquele século, há algum tempo vivia praticamente abandonado. Era usado pela prefeitura como um depósito de materiais apreendidos de camelôs e uma espécie de garagem de um clube de automóveis antigos. Um muro que separava a rua Constanza do Tendal teve que ser derrubado para a entrada do grupo. Conta-se que neste dia, um cadáver foi encontrado naquele espaço 
Memórias do Programa Vocacional: movimentos ao redor de emancipação, igualdade e política

abandonado. A invasão e ocupação geraram um "espetáculo de rua com 200 atores e mais de 1500 pessoas assistindo", conta Celso Frateschi para lembrar algumas das inspirações para a criação do Núcleo Vocacional de Teatro em $2001^{4}$.

Figura 2: Tendal da Lapa no início do século XX. Fonte: Blog do Centro Cultural Tendal da

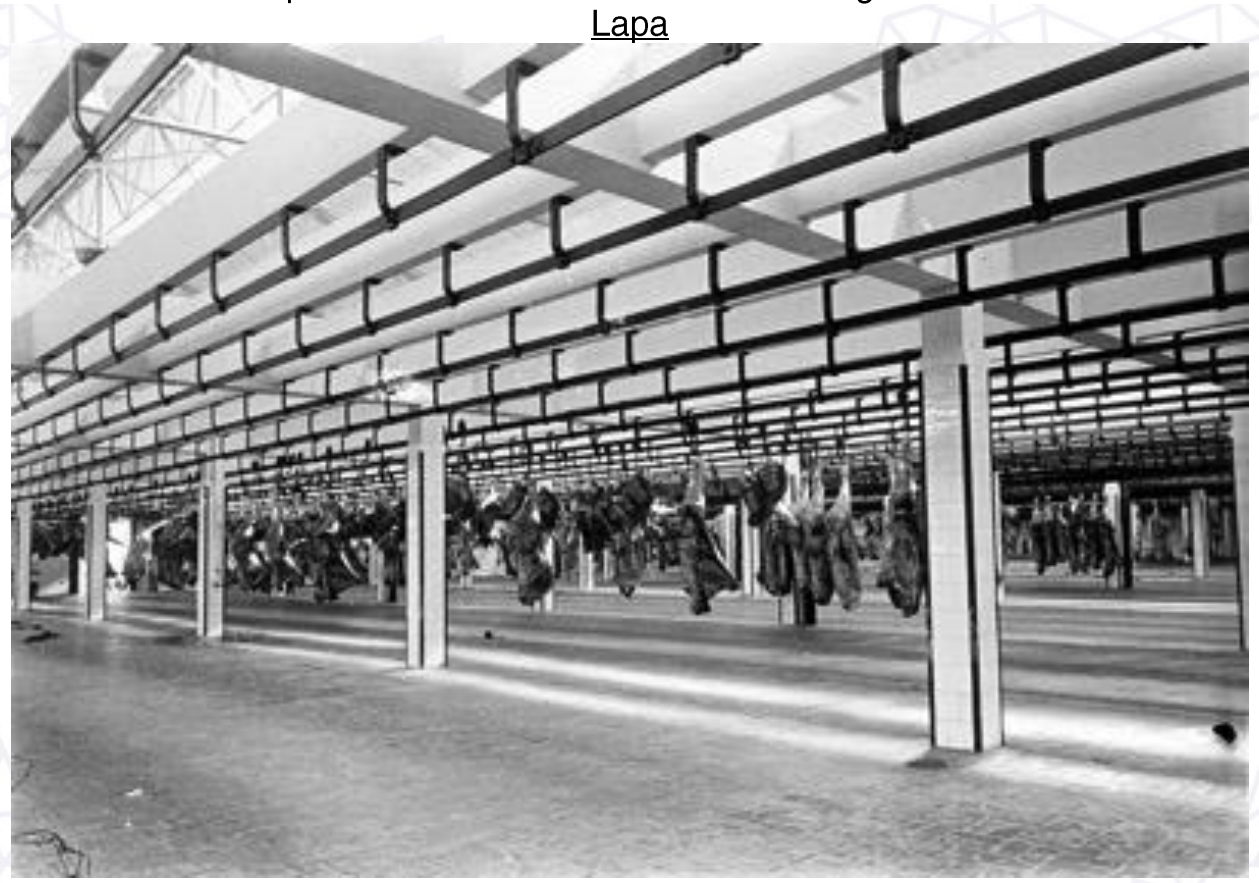

O Núcleo Vocacional surgiu ligado a outras políticas públicas e a um determinado contexto. No final de 1999 e início dos anos 2000, uma parcela da classe artística brasileira, principalmente grupos e coletivos teatrais de São Paulo, se organizaram no movimento Arte Contra a Barbárie. Foram encontros e reuniões que geraram manifestos afirmando a necessidade de arte, teatro e o papel do Estado na garantia dessa necessidade:

Para que o país encontre o caminho da promoção das humanidades e se afaste da barbárie, oficial e não-oficial, são necessárias medidas urgentes e concretas. Em nossa área, isso significa o

${ }^{4}$ Ver Vocacional Memória: percorrendo vozes e ecos de um projeto público, p. 19. Só a partir de 1992 o Tendal da Lapa passou a ser reconhecido como espaço público da Secretaria Municipal de Cultura. Em todos esses anos o local passou por mudanças e reformas confluindo atuações da sociedade civil e do poder público. Atualmente é o Centro Cultural Tendal da Lapa. 
fomento da produção artística continuada e comprometida com a formação crítica do cidadão. (III Manifesto Arte Contra a Barbárie) ${ }^{5}$

Em 2001, a gestão de Marta Suplicy, na época do Partido dos Trabalhadores (PT), assumiu a Prefeitura de São Paulo. Marco Aurélio Garcia foi, inicialmente, nomeado para a Secretaria Municipal de Cultura, cargo que Celso Frateschi ocuparia a partir de 2002. O programa apresentado pela prefeitura à época era composto por três grandes eixos: "a sociabilização dos bens culturais; a veiculação e a difusão de uma produção oculta na/da cidade; a elaboração de um pensamento estético crítico que refletisse as questões mais relevantes do século XX" (TENDLAU, 2012, p.92). Neste sentido, como políticas do, então, Departamento de Teatro, destacamos as criações: do Núcleo de Teatro Vocacional; do Programa de Formação de Público; da Ocupação dos Teatros Distritais por grupos de teatro profissionais e da Lei 13.279/02, que instituiu o Programa Municipal de Fomento ao Teatro para a Cidade de São Paulo. Neste contexto, ainda confluiu com essas ações a criação dos Centros de Educação Unificados (CEUs). Espaços intersecretariais (Cultura, Educação e Esporte), que em sua proposta, além das três Secretarias, tinham em seu Conselho Gestor a participação da população do entorno. Foram construídos de forma a pensar a educação como espaço público que pode reunir escola, biblioteca, tele-centro, teatro, piscina, quadra poliesportiva, pista de skate, entre outras atividades. Relacionado a todo este contexto foi pensado o Vocacional.

${ }^{5} \mathrm{O}$ trecho está contido no Terceiro Manifesto da Arte Contra a Barbárie, disponível no site: http://www.artes.com/reflexoes/ref39.htm acessado em 09/07/2021. 
Memórias do Programa Vocacional: movimentos ao redor de emancipação, igualdade e política

Figura 3: Trecho da página 27 da publicação Vocacional Memória

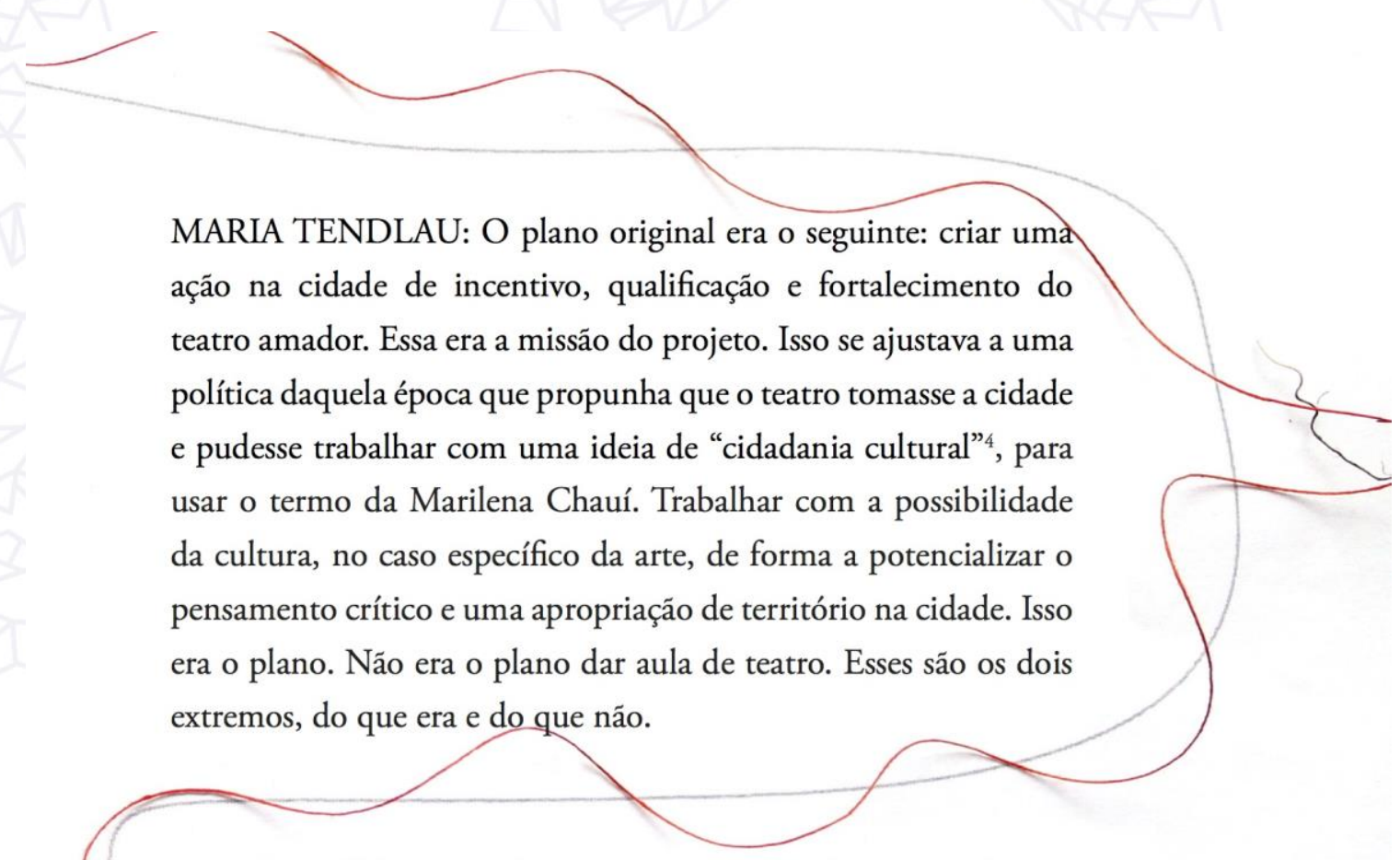

CELSO FRATESCHI: A ideia que a gente tinha não era formar

Em 2005, com a troca na gestão municipal, foram descontinuadas algumas políticas que citamos. O próprio Núcleo de Teatro Vocacional só continuou por pressão da sociedade civil, diálogo direto com a prefeitura e talvez por acaso ${ }^{6}$. Mas, ao invés de encerrado, a proposta do Núcleo de Teatro foi se expandindo. Em 2007, foi criado o Núcleo de Dança Vocacional, e no ano seguinte, o Núcleo de Música. Em 2009, os núcleos viraram um programa e as artes visuais foram incorporadas. Mais recentemente, em 2015, a literatura também entrou para o Vocacional. Ao longo desses anos, além das cinco, assim chamadas, linguagens artísticas: teatro, dança, música, artes visuais e literatura; o Vocacional também se organizou a partir de várias estruturas. Foram núcleos de encenação, artes integradas, mediação, Vocacional Apresenta, grupos de trabalhos temáticos (GTs), articulação por

\footnotetext{
${ }^{6}$ Conta-se que essa permanência foi graças a um artista vocacionado que, numa solenidade em um CEU, questionou pessoalmente o, então, prefeito José Serra (PSDB) do porquê do suposto encerramento do núcleo e a necessidade de sua continuidade.
} 
linguagem, articulação por região e articulação por áreas específicas (processos artístico-pedagógicos, instrumentais e pesquisa, comunicação e divulgação).

Todos esses movimentos reunidos neste último parágrafo deram-se em anos de diálogos entre sociedade civil e poder público, construções em conjunto, em separado, em meio a precariedades e pressões por mudanças. Por não se tratar de uma lei, de certa forma o Vocacional sempre se manteve em deslocamento, nem sempre de expansão ou aprofundamento e mesmo, a cada ano, convivendo com o risco de uma possível não continuidade das ações dos artistas. Por esses caminhos, 20 anos depois da criação de uma proposta para a cidade, pensemos, em linhas gerais, que podemos observar uma série de ações para abrir um lugar de experimentação e criação artística para qualquer pessoa da cidade, seja em artes visuais, dança, literatura, música, ou teatro. Um encontro de artistas profissionais, amadores, orientadores e vocacionados. 
Figura 4: Página 60 Vocacional Memória.

YVES REMONT (Artista Vocacionado): Sou músico, toco violáo e guitarra. Minha entrada no Vocacional foi $100 \%$ caótica. No meio de 2010 , eu estava com um amigo meu e ele me disse que havia um espaço no Centro Cultural da Juventude onde a galera se reunia pra tocar. Lá eu conheci a artista orientadora de música. Nossa intenção, no Vocacional, era montar uma banda de heavy metal e destruir por aí, pelo bairro (risos na sala). Éramos três, na época, dentro do Vocacional: dois guitarristas e um trompetista e chegamos à conclusão que náo daria para montar uma banda de heavy metal nessa configuração e com esse número de pessoas.

CELSO FRATESCHI: Fico em dúvida se as propostas do Vocacional para o teatro têm alguma coisa a ver com as questóes das artes plásticas, por exemplo. Pode até ser que tenha a ver. Mas me parece que a própria ideia do Vocacional era lidar com as particularidades, lidar com o que acontece com o material que se está trabalhando. Uma das grandes necessidades nossas era buscar a beleza a partir do material que a gente tinha e náo criar um modelo e tentar impor este modelo para o grupo que a gente estava trabalhando. Mas nós nunca vamos conseguir fazer uma escultura de metal em barro. É diferente. A técnica que se usa para o barro é diferente da do metal. Como eu acho que é 60 para as diferentes linguagens artísticas também. 
Figura 5: Página 61 Vocacional Memória.

YVES REMONT (Artista Vocacionado): Nossa artista orientadora deu uma ideia de pegarmos os instrumentos, irmos aos horários de orientação, começar a conversar e ver como a gente se arranjaria. Entáo fomos, eu e o Bruno com o violáo, o Leandro com o trompete, paramos na frente dela, e perguntamos: o que a gente faz agora? Ela perguntou: o que vocês querem fazer? Um processo de composição? A gente disse que sim. Ela pediu pra gente tocar alguma coisa e que na colocou a gente no caminho: esse é o cara, é isso que ele faz, é importante que se saiba. E ela começou a nos ensinar harmonia sem mencionar a palavra harmonia para náo corrermos o risco de cair num abismo de conceitos teóricos de música. Começamos a compor uma suíte que chamamos de "A morte do toureador". Nosso método era: um traz uma coisa, outro pega e faz outra, outro faz outra, mostramos uns pros outros, interferimos e começamos a compor juntos. E esse processo,

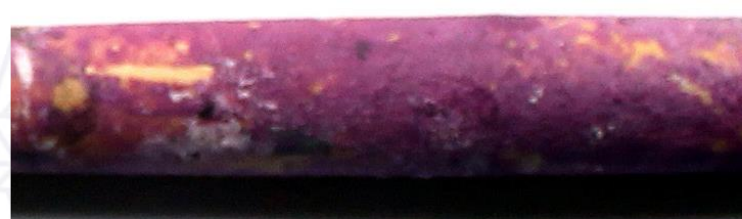

próxima orientaçáo levaria material pra gente pesquisar um processo de composiçáo. Entáo começamos a fazer barulho (risos na sala). Hoje, eu acho que a intervenção dela foi divina, mas na época foi uma crueldade, porque na semana seguinte ela trouxe uma parte do tratado de harmonia do Schoenberg. Ele foi um cara que sintetizou, num tratado todo, o nosso possível conceito de harmonia. Era uma apostila toda em espanhol, de um cara que a gente nunca tinha estudado, falando de coisas extremamente difíceis. Mas ela de agosto até novembro de 2010, foi um mapa escuro onde a gente tinha que descobrir todos os relevos, todos os cânions, todos os milhóes de abismos para poder caminhar nesse mundo completamente novo. E entáo conseguimos deixar a suíte tocável. Daí veio o sério problema da instabilidade do Programa com a saída da orientadora. Nós seguimos nos reunindo, mesmo sem a artista orientadora e demos continuidade no processo, com todo apoio do Centro Cultural da Juventude. 
Desviemos para uma outra história em que um livro foi colocado entre pessoas, neste caso, entre professor e alunos. Sobrevoando um pedaço de uma história distante, que de certa forma, já encontrou com a nossa por uma outra via. Entre 2010 e 2011, artistas do Vocacional compuseram um "material norteador", em que se pensava a "atuação do artista orientador e coordenador como mestres ignorantes"'. Em referência ao livro bem conhecido de Jacques Rancière: O mestre ignorante: cinco lições sobre a emancipação intelectual (RANCIÈRE, 2008) - o problema das referências no Vocacional virá à tona mais adiante. Menos conhecida que Rancière e o próprio "princípio do mestre ignorante" ainda abordado no edital do programa, lembremos da "aventura intelectual" de Joseph Jacotot, neto de carpinteiro que se tornou professor de literatura francesa, um revolucionário francês em 1789, que Rancière se deparou no final do século passado e quis contar para tratar da emancipação intelectual (RANCIÈRE, 2008).

Uma história, como dissemos, em que um livro foi colocado entre professor e alunos. Por contingências de um exílio na região dos Países Baixos, Jacotot, sem falar a língua de seus alunos holandeses, acabou por Ihes ensinar francês, tendo em comum somente um livro traduzido nessas duas línguas e a tarefa de atravessá-lo. Sem lhes fornecer nenhuma outra explicação, sem falar a língua deles, Jacotot constatou que tinha ensinado francês a seus alunos. Mais do que isso, a experiência de improviso fez com que ele notasse algo mais importante do que o francês ensinado: não era o aluno que necessitava das explicações do mestre para diminuir a distância entre ignorância e inteligência, mas, ao contrário, seriam as próprias explicações que criariam essa distância e faziam o aluno acreditar que não era capaz de compreender alguma coisa sozinho. Compreender não seria mais do que traduzir:

fornecer o equivalente de um texto, mas não sua razão. Nada há atrás da página escrita, nenhum fundo duplo que necessite do trabalho de uma inteligência outra, a do explicador; nenhuma língua do mestre, nenhuma língua da língua cujas palavras e frases

\footnotetext{
${ }^{7}$ Ver (Revista Vocare, 2011, p.23) disponível em: https://issuu.com/divform/docs/vocare1_2012 acessado em 09/07/2021.
} 
tenham o poder de dizer a razão das palavras e frases de um texto. (RANCIÈRE, 2008, p.27)

Jacotot "causara escândalo ao afirmar que um ignorante pode ensinar a outro ignorante aquilo que ele mesmo não sabe, ao proclamar a igualdade das inteligências e opor emancipação intelectual à instrução pública" (RANCIÈRE, 2012, p. 7). Jacotot formulou um "método universal" em que qualquer pessoa poderia ser causa de ensino para outra pessoa. Em que pais analfabetos poderiam alfabetizar seus filhos, por exemplo. Ele mesmo, Jacotot, ensinou música e pintura, "duas matérias em que sua incompetência era patente" (RANCIÈRE, 2008, p. 27).

Jacques Rancière relembra a história de Jacotot para tratar da emancipação intelectual num contexto em que se debatia na França o papel do Estado na instrução e formação das pessoas e o problema da redução das desigualdades. $\mathrm{O}$ argumento de Rancière constatado com Jacotot é que não haveria um "dever" do estado na eliminação da distância entre as inteligências, mas sim possibilidades de ação a partir de uma suposição radical de igualdade das inteligências. Uma lógica, segundo Rancière e Jacotot, oposta e dissonante do que se construía como "sociedade pedagogizada", em que se atribuía ao ensino a tarefa da redução da desigualdade social, partindo da redução da distância entre os supostos ignorantes e o saber:

\begin{abstract}
A distância que a Escola e a sociedade pedagogizada pretendem reduzir é aquela de que vivem e não cessam de reproduzir. Quem estabelece a igualdade como objetivo a ser atingido, a partir da situação de desigualdade, de fato a posterga até o infinito. A igualdade jamais vem após, como resultado a ser atingido. Ela deve ser sempre colocada antes. A própria desigualdade social já a supõe. (RANCIĖRE, 2008, p.11)
\end{abstract}

É neste sentido que a igualdade não pode ser o dado que uma política aplica, ou essência que uma lei encarna, nem objetivo que ela se propõe atingir, seria "apenas uma pressuposição que deve ser discernida nas práticas que a põem em uso" (RANCIÈRE, 1996, p. 45). Antes de voltar ao Vocacional, repousemos nessa palavra política, tão utilizada no programa. Sigamos com o autor Rancière e o que ele desvia e inverte nesse entendimento. 
Memórias do Programa Vocacional: movimentos ao redor de emancipação, igualdade e política

A política, como a compreendemos, viria da tentativa de repartir as parcelas do comum por um equilíbrio outro, que não o da dominação. Ou seja, para que uma comunidade fosse mais do que "um contrato entre quem troca bens ou serviços, seria preciso que a igualdade que nela reinasse fosse radicalmente diferente daquela segundo a qual as mercadorias se trocam e os danos se reparam" (RANCIÈRE, 1996, p. 21). Ou seja, a política, incialmente, poderia ser compreendida como "a interrupção dos simples efeitos da dominação dos ricos" (RANClÈRE, 1996, p. 26). Mas seria a igualdade como uma "parcela dos sem parcela" pesada nessa nova balança, o que de fato institui a política. Neste sentido, a inversão de que trata Rancière se refere ao que:

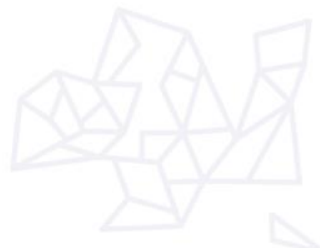

chamamos geralmente pelo nome de política, o conjunto dos processos pelos quais se operam a agregação e o consentimento das coletividades, a organização dos poderes, a distribuição dos lugares e funções e os sistemas de legitimação dessa distribuição. Proponho dar outro nome a essa distribuição e ao sistema dessas legitimações. Proponho chamá-la de polícia (...). Proponho agora reservar o nome de política a uma atividade bem determinada e antagônica à primeira: a que rompe a configuração sensível na qual se definem as parcelas e as partes (...) a atividade política é a que desloca um corpo do lugar que lhe era designado ou muda a destinação de um lugar; ela faz ver o que não cabia ser visto, faz ouvir um discurso ali onde só tinha lugar o barulho, faz ouvir como discurso o que só era ouvido como barulho. (RANCIÈRE, 1996, p. 42, grifos do autor)

Podemos pensar política como um "processo da igualdade", entendendo esse termo como um "conjunto aberto das práticas guiadas pela suposição da igualdade de qualquer ser falante com qualquer outro ser falante e pela preocupação de averiguar essa igualdade" (RANCIÈRE, 1996, p. 43). 
Figura 6: Página 58 Vocacional Memória.

JHOW (Família Justa Causa): Eu sempre cantei rap. Mas era dentro de outra linguagem, que tinha mais a ver com protesto. $\mathrm{Na}$ época, eu pensava que gostaria de fazer uma música diferenciada e que todo mundo pudesse curtir. Em 2008, foi quando ficamos sabendo do Vocacional e tivemos nosso primeiro artista orientador, no CEU Lajeado, em Guaianazes. Ficamos com ele um ano, aprendemos algumas coisas e, em 2009, tivemos outra artista orientadora e começamos a desenvolver mais nosso canto, nosso comportamento e nossa fala. Começamos a pesquisar $\mathrm{MPB}$, samba e náo ficamos só no rap. Porque o rap a gente já tinha nascido escutando. A artista orientadora propôs novas coisas e acabou enriquecendo nosso trabalho. A Família Justa Causa é formada por mim, pelo meu cunhado, meu sobrinho... somos uma família mesmo, em seis pessoas. Meu sobrinho tem 10 anos hoje, mas quando entrou com a gente no Vocacional ele tinha 5 , nem falava direito. Passou o ano de 2009, a gente viu que estava num patamar legal e decidiu fazer shows. Aí entramos no Vocacional Apresenta. Era muito legal esse projeto, porque íamos para vários equipamentos aqui em Sáo Paulo. Eu sei que o Vocacional e o Vocacional Apresenta sáo projetos diferentes, mas foi no Apresenta que vimos a dificuldade do Programa. Nós náo tínhamos nenhuma ajuda de custo e colocávamos tudo do próprio bolso. E também tinha o problema da divulgaçáo. Náo havia. Náo tinha público. Às vezes tinha público no CEU porque a gente fechava com o pessoal do EJA (Ensino para Jovens e Adultos), mas quando náo tinha, a gente apresentava para duas pessoas... Lógico que o legal náo é, necessariamente, a quantidade de gente vendo, mas sim a evoluçáo do nosso trabalho. 
Memórias do Programa Vocacional: movimentos ao redor de emancipação, igualdade e política

Figura 7: Página 64 Vocacional Memória

GABRIEL ANDRIOLA (Artista Vocacionado): Esse é meu terceiro ano de Vocacional no CEU Casa Blanca. Eu entrei porque minha mãe ouviu falar. Eu, na verdade, cheguei lá para fazer tênis, mas acabei vendo a plaquinha do Vocacional e me interessei. Dentro do teatro é muito acolhedor. Lá fiz amigos que provavelmente vou levar para a vida toda. Mas eu mesmo não quero fazer teatro. Mas estar lá me fez pensar em outras coisas. Eu mesmo sou mais desenhista. Mas estar com as pessoas lá dentro e o processo que o artista orientador faz me estimula muito a procurar mais coisas. $\mathrm{O}$ teatro mexe muito com o imaginário. A imagem em si. E como quero seguir a carreira de desenhista, pintor, dentro da arte isso me enriquece muito mais. Dentro do teatro não é só o Teatro. A gente discute muito. Eu já briguei com artista orientador inúmeras vezes, ainda brigo até hoje. E isso vai me transformando e amadurecendo. É legal quando se está com o outro e começa a ter ideias que não batem. 
Voltando ao programa, antes de encerrar, façamos uma última mirada para trás sobre o Vocacional com um olhar crítico para nós mesmos. Agora em movimento de Sankofa, ideograma de um pássaro com a cabeça voltada para trás, pertencente ao conjunto adinkra dos povos Akan (grupo étnico de povos habitantes na região leste da Costa do Marfim e de Gana). Sankofa significa: "nunca é tarde para voltar e apanhar o que ficou para trás, (...) constitui o símbolo da sabedoria de retornar ao passado, como maneira de melhorar o presente e construir o futuro" (OLIVEIRA, 2016, p.15). Esta é a primeira referência de autor não branca apresentada neste ensaio de um autor branco pensando emancipação e igualdade. Na verdade, não a primeira se contarmos os depoimentos dos artistas vocacionados.

Ao longo da maioria de seus 20 anos, o Vocacional contou com majoritariamente artistas brancos, partindo de perspectivas quase sempre de autores europeus, atuando na maioria das vezes em territórios em que a maioria não era branca. Desde 2015, grupos de trabalho passaram a observar com mais atenção as questões de gênero e étnico-raciais dentro do Vocacional e passaram a lutar por reparação e garantia de direitos. A estrutura do programa começou a sofrer mudanças mais significativas, o perfil dos artistas foi se tornando mais diverso, vocacionados dos primeiros anos passaram a se tornar orientadores, articuladores, coordenadores. Foram processos de luta, diálogo e escuta. Seguindo sua trajetória de encontros, experimentações e propostas artístico pedagógicas, o último edital publicado para contratação dos artistas para o programa em 2021, pela primeira vez, contou com ações afirmativas. Foram reservadas, preferencialmente, 56\% das vagas dos contratados para pessoas autodeclaradas pretas, pardas ou indígenas e pela modalidade bônus, foram pontuadas a mais no processo seletivo pessoas transexuais, travestis, transgêneres e pessoas com deficiência.

Ações que interferem no modo do Vocacional se organizar e atuar, que permitem que ainda faça sentido a existência dessa política pública de 20 anos. Permitindo soar para toda a estrutura do poder público a necessidade de ação a partir dos territórios que compõem essa cidade. Fechemos com 
Memórias do Programa Vocacional: movimentos ao redor de emancipação, igualdade e política

palavras do filósofo Renato Noguera, aventando novas memórias e "pluriversalidades" para os próximos 20 anos do Vocacional:

A educação não pode ser entendida como a busca por um "modelo" único, um elogio ingênuo da "monorracionalidade". Na sociedade brasileira, o desafio pode ser descrito como o esforço de escapar da concepção abstrata de igualdade, do currículo universal que se alicerçava no mérito e na neutralidade tendo como fiador a visão monocultural das sociedades ocidentais. (...) A pluriversalidade é o reconhecimento de que todas as perspectivas devem ser válidas; apontando como equívoco o privilégio de um ponto de vista. Com efeito, cabe-nos sustentar que a filosofia é um exercício pluriversal de pensamento. A filosofia entendida como universal estaria ligada à educação entendida como um território com centro e periferias. Por outro lado, a pluriversalidade filosófica aqui defendida concebe a educação como um exercício policêntrico, perspectivista, intercultural que busca um polidiálogo considerando todas as particularidades. (NOGUERA, 2012, p. 62-73)

\section{Referências Bibliográficas}

CHAUÍ, Marilena. Cidadania Cultural: O direito à cultura. São Paulo: Editora Fundação Perseu Abramo, 2006.

MONTAIGNE, Michel de. Ensaios. Trad. Sérgio Milliet. São Paulo: Abril Cultural, 1972.

NOGUERA, Renato. Denegrindo a educação: um ensaio filosófico para uma pedagogia da pluriversalidade. Revista Sul-Americana de Filosofia e Educação.

Número 18: maio-out/2012.

PUPO, M. L. S. B. Quando a cena se desdobra: as contrapartidas sociais. In:

DESGRANGES, Flávio; LEPIQUE, Maysa (Orgs.). Teatro e vida pública - 0

Fomento e os coletivos teatrais de São Paulo. São Paulo: Hucitec: Cooperativa

Paulista de Teatro, 2012, p. 152-173.

OLIVEIRA. Alan Santos de. Sankofa: A circulação dos provérbios africanos oralidade, escrita, imagens e imaginários. 2016. 120f. Dissertação (Mestrado em Comunicação) - Curso de Pós-Graduação em Comunicação, Universidade de

Brasília, 2016. Disponível em https://repositorio.unb.br/handle/10482/20735 acessado em: 09/07/2021

RANCIÈRE, Jacques. O desentendimento. Trad. Ângela Leite Lopes São Paulo: Editora 34, 1996.

O espectador emancipado. São Paulo: Martins Fontes, 2012. 
O mestre ignorante: cinco lições sobre a emancipação intelectual.

Trad. Lílian do Valle. Belo Horizonte: Editora Autêntica, 2008.

TENDLAU, Maria. As primeiras edições do Fomento e a gestão Garcia-Frateschi na Secretaria Municipal de Cultura (2001-2004). In: DESGRANGES, Flávio; LEPIQUE, Maysa (Orgs.). Teatro e vida pública - O Fomento e os coletivos teatrais de São Paulo. São Paulo: Hucitec: Cooperativa Paulista de Teatro, 2012, p.87-99.

\section{Links Consultados}

Blog do Centro Cultural Tendal da Lapa. Disponível em:

http://tendaldalapa.blogspot.com/p/tombamento.html acessado em 09/07/2021.

Centro de Memória e Documentação Supervisão de Formação Cultural. São

Paulo, 2019. Disponível em:

http://supervisaodeformacao.prefeitura.sp.gov.br/index.php/supervisao-formacaocmd/ acessado em: 09/07/2021.

Manifestos do Movimento Arte Contra a Barbárie. Disponível em:

http://www.artes.com/reflexoes/ref39.htm acessado em: 09/07/2021.

Revista Vocare, Revista do Vocacional: Edição comemorativa de 10 anos. São Paulo, nº1, p.1-96, novembro de 2011. Disponível em:

https://issuu.com/divform/docs/vocare1 2012 acessado em: 09/07/2021

Vocacional Memória: percorrendo vozes e ecos de um projeto público. São

Paulo, 2017, s/n, dezembro, p.1-108, dezembro de 2017. Disponível em:

https://issuu.com/1miguelprata/docs/vocacionalmemo riafinal acessado em:

09/07/2021. 